\title{
New section: Memories and Retrospectives
}

\author{
Klaus Eichmann
}

/ Published online: 18 May 2013

(C) Springer Basel 2013

Recently, CMLS has changed the name of the section Memories of a Senior Scientist into Memories and Retrospectives. The change of the name is connected with a change in scope. Formerly, this section contained mostly articles by elderly scientists who recalled their own career and achievements. More recently, the scope has shifted to reflections on outstanding scientific discoveries that the authors themselves had made or had been associated with in one way or another. While the latter type of article continues to be eligible in Memories and Retrospectives, the former is discontinued. Instead, CMLS invites articles dealing with the history of scientific notions (discoveries, theories, paradigms, etc.) that have contributed to or resulted in lasting scientific knowledge, in the laboratory or in practical reality. The first article of this type: "Fred Neufeld and pneumococcal serotypes: Foundations for the discovery of the transforming principle", by myself and Richard M. Krause, my lifelong teacher and friend, may serve as just one example (CMLS 2013, Vol. 70, this issue, doi: 10.1007/s00018-013-1351-z).

CMLS does not intend to compete with journals of scientific or medical history. The above-mentioned paper was sent out for review to science historians and some of their comments are quoted here to clarify the issue. One reviewer wrote: "On condition that this is not the work of professional historians but of retired experts of the field (this is clearly stated which I like), I find this a valuable and interesting contribution". Another reviewer remarks: "The authors do a good job of presenting Neufeld's work....., but it is difficult to evaluate their assessment of Neufeld,

K. Eichmann $(\bowtie)$

Max-Planck-Institute of Immunobiology and Epigenetics,

Stübeweg 51, 9108 Freiburg, Germany

e-mail: eichmann@immunbio.mpg.de partly because they do not discuss secondary literature to any extent," and continues: "The article would be greatly enriched by employing a...discussion of socio-historical contexts and problems surrounding scientific work (without such an approach the appraisal of Neufeld's importance also risks coming across as overly simplistic)". As these comments show, articles in Memories and Retrospectives may be authored by laboratory scientists, including retired ones, may concentrate on primary rather than secondary literature, and may focus on the scientific rather than on the socio-historical context. In other words, we accept a degree of "simplicity" - in the judgment of science historians that publish in professional history journals.

Indeed, science historians usually are interested in the social and cultural stipulations of scientific approaches to problem-solving. They care less about the question whether a scientific approach has, or has not, yielded a scientific fact of lasting validity, or weather it has contributed, by verification or falsification, to present-day scientific knowledge. Those of us who reflect on their own work are well aware that much of our everyday scientific endeavor may be of immediate excitement but whether or not it proves consequential in the long run is an entirely different matter. Thus, while science historians care about the development of thought and opinion, laboratory scientists are primarily interested in the history of the generation of facts, i.e., in the intricate, unforeseeable, unplannable avenues by which scientific endeavor evolves into robust knowledge.

The new section Memories and Retrospectives invites articles that aim at analyzing this process, which can only be done by looking into research of the past and its influence on the present, by studying the work of creative scientists and the landmarks they have left on the pathway to robust knowledge. We hope that, over time, a collection of articles will be assembled that together shed light 
on putative common denominators, if any, in the process of cognition in the life sciences. Submitted articles will be screened for scope and interest and successful articles will be submitted to peer review, including historian reviewers. Like any other article published by CMLS, papers in the section Memories and Retrospectives must be based on sound scientific analysis, with subjective opinion kept at a minimum. Historical and scientific accuracy is an absolute requirement, as well as novelty in focus and interpretation.
Of note, manuscripts by authors that primarily try to raise attention for their own previous accomplishments are definitively discouraged. Needless to stress, Memories and Retrospectives will remain a minority section in CMLS, which continues to specialize in review articles and original papers in the cutting-edge life sciences.

Klaus Eichmann

Editor-in-Chief 